\title{
An Experimental Investigation of Laser Scabbling of Concrete
}

\author{
B. Peach ${ }^{\mathrm{a}, 1, * *}$, M. Petkovski ${ }^{\mathrm{a}, 2, *}$, J. Blackburn $^{\mathrm{b}}$, D.L. Engelberg ${ }^{\mathrm{c}}$ \\ ${ }^{a}$ Department of Civil and Structural Engineering, Sir Frederick Mappin Building, Mappin Street, University of Sheffield, Sheffield, S1 3JD, UK \\ ${ }^{b}$ TWI Ltd, Granta park, Great Abington, Cambridge, CB21 6AL, UK \\ ${ }^{c}$ Research Centre for Radwaste E Decommissioning, School of Materials, The University of Manchester, Manchester, M13 9PL, UK
}

\begin{abstract}
Laser scabbling of concrete is the process of removal of surface material using a high power laser beam. The main aim of this investigation was to establish an experimental procedure for assessing the effects of various parameters that may be critical for the effectiveness of the process, such as material composition and initial moisture content. The study shows that the key characteristics of the process can be detected by monitoring surface temperature variations. This experimental procedure is used to provide data on the effects of each parameter to explain the mechanisms that drive the process. The results suggest that scabbling is mainly driven by pore pressures in the cement paste, but strongly affected by other factors. Reducing permeability by adding PFA to the cement paste resulted in significant increase in volume removal; but reducing moisture content by air-drying of the material did not result in the expected reduction in volume removal.
\end{abstract}

Keywords:

Concrete, Cement, Scabbling, Spalling, Thermal Analysis

\section{Introduction}

Concrete is widely used in the nuclear industry, often in direct contact with radioactive materials. Concrete contamination tends to extend $8-12 \mathrm{~mm}$ from the surface [1]. Removal of the contaminated surface region can reduce the volume of waste requiring controlled disposal. Mechanical scabbling and high pressure water jetting have been used for surface removal in nuclear decommissioning. Water jetting produces large volumes of secondary waste, whereas mechanical scabbling involves large reaction forces, requiring extensive deployment systems unsuitable for remote handling. Application of a high power laser on a concrete surface causes concrete fragments to explosively spall from the surface. Lasers of wavelengths around $1 \mu \mathrm{m}$ can be transmitted down optical delivery fibres several hundred metres in length, allowing expensive laser gen-

\footnotetext{
${ }^{*}$ Corresponding author

** Principal corresponding author

Email addresses: bdpeach1@sheffield.ac.uk (B. Peach), m.petkovski@sheffield.ac.uk (M. Petkovski), jon.blackburn@twi.co.uk (J. Blackburn), dirk.engelberg@manchester . ac.uk (D.L. Engelberg)

${ }^{1}$ Tel: +44 (0) 1142225729

${ }^{2}$ Tel: +44 (0) 1142225759
}

eration equipment to be stationed away from contaminated areas. As no reaction forces are developed during laser scabbling, relatively lightweight deployment systems can be used, making remote handling a real possibility. Laser scabbling and surface glazing, with subsequent surface removal, was used successfully in the decommissioning of the Japan Atomic Energy Research Reprocessing Test Facility [2].

Laser scabbling is comparable to explosive spalling exhibited in concrete exposed to fire conditions, but the large difference in heating rates would be expected to produce different mechanisms driving the two processes.

\subsection{Laser Scabbling}

Laser scabbling was discovered in the early 1990's during concrete glazing investigations [3]. The phenomenon was attributed to the rapid expansion of water from cement paste dehydration. Blair [4], however, found scabbling to take place only in locations where limestone aggregate was close to the surface. A thicker mortar cover created a glazed layer preventing scabbling. Blair concluded that the scabbling was driven by the pressure of gas produced by decarbonation of calcite. 
MacCallum and Norris[5] suggested that the mechanism responsible for laser scabbling was the build up of strain in the interfacial transition zone between the aggregate and hardened cement paste. Multiple passes were ineffective suggesting a critical strain may be reached on the initial pass. The authors concluded that scabbling was caused by expansion of aggregates, and hence the beam diameter had to be sufficiently large to heat whole aggregate pieces.

Dowden et al [6] investigated, through modelling, a mechanism of laser scabbling based on the hypothesis that the laser beam causes expansion of a thin surface layer of concrete which induces internal stresses. Tensile stresses are formed beneath this layer, which are relieved through fracture and buckling of the surface, resulting in ejection.

The effect of type of coarse aggregate on scabbling has been highlighted in several studies. Nguyen [7] found that granite concrete consistently scabbled to a depth of $1.5 \mathrm{~mm}$, whereas whinstone (basalt) concrete, cored from a nuclear facility currently being decommissioned, failed to scabble for any set of laser parameters. A vitrification threshold power density was identified for basalt concrete at $103 \mathrm{~W} / \mathrm{cm}^{2}$, at higher power densities the basalt melted, creating a glazed layer that prevented scabbling. It is not clear, however, why lower power densities were insufficient to initiate scabbling. A number of factors could be responsible, such as damage caused during coring (leading to increased permeability and reduction of pore pressures) or the laser being applied to a cut rather than a cast face (different surface conditions). Hilton [8] reported similar results for basalt concretes, however limestone concrete was seen to scabble successfully for a large range of laser parameters $\left(120-960 \mathrm{~W} / \mathrm{cm}^{3}\right)$.

The effect of degree of saturation on laser scabbling has been investigated in several experiments. Blair [4] found that specimens of limestone concrete soaked overnight experienced a greater extent of scabbling. Hilton [8] also found that a wet surface increased volume removal of limestone concrete specimens but had no noticeable effect on basalt or granite concretes. Johnston found that laser scabbling was ineffective on specimens that had free water removed by heating prior to testing (reported in [6]). Rather than claiming that this was due to a reduction in pore pressure spalling, Dowden suggested that the ineffectiveness was due to a reduction in the coefficient of expansion, a reduction in the Youngs modulus, an increase in density, an increase in specific heat capacity or a reduction in strength, as a result of drying.

Stochastic scabbling behaviour has been identified in several studies $[5,7,8,9]$. Trials conducted using identical laser parameters on concretes of identical composition yielded vastly different outcomes, ranging between scabbling, vitrification and faint heat marks.

Laser beam parameters are critical for laser scabbling of concrete. A number of authors have identified threshold power densities at constant scan speeds, defined as laser power per unit area, below which concrete scabbles and above which the surface vitrifies $[2,4,5,10,11]$. Vitrification relieves strains preventing scabbling [5]. Blair [4] suggested that beam diameter had to be large enough to heat entire pieces of aggregate. MacCallum and Norris [5] went further, suggesting that laser scabbling was not a scalable function with power density and heat input, but also depended on the ratio between beam diameter and aggregate size. Blair [4] also found that trials with high power density and high scan speed resulted in the same concrete behaviour as low power density and low scan speed trials; suggesting that the rate of energy emitted by the laser, to a unit area of concrete, was the key factor determining the scabbling of concrete. Experiments carried out by MacCallum and Norris [5] using laser powers in the range $200-1000 \mathrm{~W}$ and beam diameters of $0.05 \mathrm{~mm}$ and $26 \mathrm{~mm}$ also showed that the process was dependant on heat input and diameter size. For a single pass on limestone concrete (with laser beam diameter of 60 $\mathrm{mm}$, power $5 \mathrm{~kW}$, scan speed $200 \mathrm{~mm} / \mathrm{min}$, and power density $177 \mathrm{~W} / \mathrm{cm}^{2}$ ) Hilton [9] achieved removal rates of up to $217 \mathrm{~cm}^{3} / \mathrm{min}$. Johnston and Spencer [12] compared the scabbling performance of a $\mathrm{CO}_{2}$ laser and a $N d$ : YAG laser, with wavelengths of $10.6 \mu \mathrm{m}$ and 1.06 $\mu \mathrm{m}$ respectively, and found very little difference: identical laser parameters yielded similar removal rates with slight variations in trough profiles.

\subsection{Explosive Spalling}

Explosive spalling is a phenomenon observed in concrete structures exposed to fire conditions, where the heating rates are much lower than those in laser scabbling. Connolly [13] found the temperature at the onset of spalling to be higher for a lower heat rate (varying from $130^{\circ} \mathrm{C}$ for $75^{\circ} \mathrm{C} / \mathrm{min}$ to $340^{\circ} \mathrm{C}$ for $25^{\circ} \mathrm{C} / \mathrm{min}$ ), whereas other authors reported that surface temperatures at the onset of spalling are between $300-425^{\circ} \mathrm{C}$ [14] dependant upon material composition rather than heat rate. For laser scabbling heat rates are typically around $200^{\circ} \mathrm{C} / \mathrm{s}$. The fragment sizes in the two processes are also very different: $10 \mathrm{~mm}$ depth and $30 \mathrm{~mm}$ width [8] for scabbling, and $100 \mathrm{~mm}$ depth and 200-300 mm width [14] for spalling. 
It is generally accepted that high strength concrete (water/cement $<0.4$ ) has a tendency to spall more than normal strength concrete (water/cement $>0.4$ ) $[15,16$, 17, 18]. This is attributed to the higher permeability in normal strength concrete, which allows dissipation of water pressures within the pore network. Many authors have highlighted the relationship between moisture content (degree of saturation) and spalling, with a higher moisture content leading to a greater degree of spalling [19, 20, 21, 22, 23]. It has also been reported that the higher the concrete strength the lower the moisture content required for spalling [21]. The general assumption is that this is most likely due to concrete properties affected by concrete strength, such as porosity and permeability, rather than a direct consequence of concrete strength. Hertz [20] found that dry specimens experienced spalling too, concluding that chemically bound water must have contributed towards pore pressure spalling as the source of moisture in these specimens. Copier [23] found that concrete with a moisture content below $5 \%$ will not spall, although in reality concrete will always have a moisture content of $7-10 \%$ (by volume).

Connolly [13] investigated the effects of aggregate type on spalling in experiments on concretes using limestone, gravel and Lytag (a lightweight aggregate). He found that limestone and Lytag concretes behaved similarly, with gravel concrete being the most susceptible to spalling. Lightweight aggregates are used to mitigate spalling by increasing the permeability of concrete. The lightweight aggregate, however, experienced the most violent spalling with fracture taking place within the aggregate itself, whereas in gravel and limestone concrete fractures occurred exclusively in the cement paste. Connolly suggested that the greater porosity of lightweight aggregates allowed pore pressures to build within the aggregates causing them to explode. Connolly and Khoury [13, 14] suggested that if the moisture content was high enough for saturation in the aggregate to exceed that of the cement paste, the use of lightweight aggregate would encourage spalling rather than mitigate against it .

$\mathrm{Fu}$ [19] found that spalling occurred at heat rates above $3^{\circ} \mathrm{C} / \mathrm{min}$, although Hertz [20] found heat rates as low as $1^{\circ} \mathrm{C} / \mathrm{min}$ to cause spalling in specific conditions. Hertz [20] found that the addition of silica fume (densification of concrete) affected both the initial moisture content and the heat rate required for spalling to take place. The heat rate triggering spalling decreased from 10 to $1{ }^{\circ} \mathrm{C} / \mathrm{min}$ with addition of $7 \%$ silica fume in an expanded clay aggregate concrete. Alternatively it has been suggested that steep thermal gradients caused by a high heat rate may result in formation of microcracks which release pore pressures, as shown by Phan [18], who found that specimens heated at $25^{\circ} \mathrm{C} / \mathrm{min}$ developed smaller pore pressures than specimens heated at rates of $5^{\circ} \mathrm{C} / \mathrm{min}$.

It should be noted that spalling studies have identified stochastic behaviour, in that 'identical' specimens exposed to 'identical' conditions did or did not spall for unexplained reasons [14].

\subsection{Scope and Aim of the Research}

Previous studies show that there are some similarities between explosive spalling and laser scabbling. Both processes result in explosive fragment ejection, are influenced by moisture content and may exhibit stochastic behaviour. On the other hand, the rather limited previous research on laser scabbling showed some very significant differences have been observed between the two processes The heating rates and maximum temperatures reached during scabbling are higher and aggregate type affects the two processes in opposite ways: siliceous aggregates tend to enhance explosive spalling but hinder laser scabbling. When a high power laser beam is applied to concrete surfaces the material either scabbles (explosive ejection of fragments) or vitrifies, although stochastic tendencies have also been reported. A threshold input energy per unit area $\left(W /\left(s \cdot \mathrm{mm}^{2}\right)\right)$ exists, below which the material scabbles, and above which it vitrifies (and further scabbling is hindered). The process of laser scabbling is also highly sensitive to aggregate type and a higher moisture content enhances the process.

The aim of this research was to establish an experimental methodology for detecting the mechanisms responsible for laser scabbling of concrete. To achieve this the investigation focussed on the following objectives:

(1) Detect key characteristics of scabbling behaviour: surface temperature at the onset of scabbling, temperature changes during scabbling and relationship between surface temperature variations and volume removal (volume removal rate, size of fragments and frequency of ejections).

(2) Establish relationships between surface temperature, scabbling behaviour and chemical changes in the material.

(3) Determine the differences in scabbling behaviour between different materials (different compositions and initial moisture contents) in order to isolate key factors and/or mechanisms responsible for laser scabbling. 
Table 1: Mix compositions (All measurements in mass:binder ratio unless otherwise stated. * AGR mix is included for comparison only; not tested in the experimental programme. ** Basalt and Limestone Concrete refer to concrete mixes using basalt and limestone as coarse aggregates.).

\begin{tabular}{|c|c|c|c|c|c|c|}
\hline & *AGR & $\begin{array}{r}* * \text { Limestone } \\
\text { Concrete (LC) }\end{array}$ & $\begin{array}{r}* * \text { Basalt } \\
\text { Concrete }(\mathrm{BC})\end{array}$ & $\begin{array}{r}\text { Mortar } \\
(\mathrm{M})\end{array}$ & $\begin{array}{r}\text { PFA+OPC } \\
\text { Paste (P) }\end{array}$ & $\begin{array}{r}\text { OPC } \\
\text { Paste }(\mathrm{O})\end{array}$ \\
\hline Water & 0.42 & 0.42 & 0.42 & 0.42 & 0.42 & 0.42 \\
\hline OPC & 0.75 & 0.75 & 0.75 & 0.75 & 0.75 & 1 \\
\hline PFA & 0.25 & 0.25 & 0.25 & 0.25 & 0.25 & \\
\hline Fine agg. & 1.84 & 1.84 & 1.84 & 1.84 & & \\
\hline Plasticiser & 0.0045 & 0.0045 & 0.0045 & & & \\
\hline $10 \mathrm{~mm}$ agg. & 1.05 & 3.21 & 3.21 & & & \\
\hline $20 \mathrm{~mm}$ agg. & 2.16 & & & & & \\
\hline $\mathrm{w} / \mathrm{c}$ & 0.56 & 0.56 & 0.56 & 0.56 & 0.56 & 0.42 \\
\hline$\%_{(m)}$ solids & 78 & 78 & 78 & 56 & 0 & 0 \\
\hline$\%_{(m)}$ cem. paste & 22 & 22 & 22 & 44 & 100 & 100 \\
\hline
\end{tabular}

\section{Materials, Specimens, Test Set-up and Experi- mental Programme}

The experimental programme described here is the first stage in a larger study of laser scabbling of concrete. This programme was designed to explore a wide range of parameters in order to develop an experimental methodology, identify the factors that have a major effect on the process and potentially obtain data that can be used to explain the mechanisms responsible for laser scabbling of concrete. The factors identified in this programme will be used as a basis for planning of experiments in the following stages of the study.

\subsection{Materials and Specimen Preparation}

The material compositions selected for this study (Table 1) were based on the concrete composition of the pre-stressed concrete pressure vessel of the advanced gas cooled reactor (AGR) in the Heysham-2 nuclear power station in Lancashire, UK.

The materials used for preparing the test specimens were: Hanson CEM I OPC (strength class $52.5 \mathrm{~N}$ ); CEMEX pulverised fuel ash (PFA; LOI-B and finenesss); fully graded marine dredged quartzitic sand from Hoyle Bank, Morecombe Bay, UK; crushed basalt rock sourced from High Force Quarry, Durham, UK; and crushed limestone rock from Longcliffe Quarry, Derbyshire, UK.

All mixes underwent 30-60 seconds dry mixing followed by 3-5 minutes wet mixing. The slurry was transferred to $100 \mathrm{~mm}$ cube moulds which were 3/4 filled and vibrated for approximately 10s before being filled and vibrated again for approximately $10 \mathrm{~s}$, and the cast face trowelled smooth. All specimens underwent a ten day temperature matched curing regime reaching a peak temperature of $65^{\circ} \mathrm{C}$ after 36 hours, gradually returning to $20^{\circ} \mathrm{C}$ after 240 hours. After curing, the $100 \mathrm{~mm}$ cubes were cut in half using a diamond saw, creating $100 \mathrm{~mm} \times 100 \mathrm{~mm}$ x $49 \mathrm{~mm}(+/-1 \mathrm{~mm})$ cuboid specimens, which were stored in a mist room at $100 \%$ relative humidity and approximately $20^{\circ} \mathrm{C}$ for 50 days.

All specimens tested in this study are detailed in Table 2. Two degrees of saturation were investigated in the test programme: saturated and air dried. Saturated specimens remained at $100 \%$ relative humidity until tested, whereas air dried specimens were stored at approximately $40 \%$ relative humidity and $20^{\circ} \mathrm{C}$ from 50 days of age to the time of testing (between 49-65 days of conditioning). Laser scabbling is a surface procedure and therefore all experiments were carried out on a 'cast' surface rather than cut and polished surface. Limestone and basalt rock, sourced from the same quarries as the crushed aggregates, was machined to $100 \mathrm{~mm}$ x $100 \mathrm{~mm}$ x $49 \mathrm{~mm}(+/-1 \mathrm{~mm})$ specimens.

\subsection{Laser Beam Parameters}

All scabbling tests were carried out using an IPG Photonics YLS-5000 (5 kW) YB-fibre laser. The specimens were subjected to a static, continuous, diverging laser beam with a stand off distance of $340 \mathrm{~mm}$ from the focal point.This setup is different from normal laser scabbling applications, where the beam moves along the surface at a predetermined speed. The static beam was chosen to allow better control of the experiments.

Laser parameters used in this study $(4.76 \mathrm{~kW}$ power at the workpiece, $60 \mathrm{~mm}$ nominal diameter) were similar to those that gained the deepest trough profile in the most recent NDA funded trial at TWI Ltd [9]. A scabbling depth of $22 \mathrm{~mm}$ was reported after application of laser beam using laser parameters of $5 \mathrm{~kW}$ requested power, $60 \mathrm{~mm}$ nominal diameter and $100 \mathrm{~mm} / \mathrm{min}$ scan speed, on limestone concrete. The maximum interaction time for any area of concrete (the centre of the beam) 
Table 2: Experimental programme and test specimens. (Las. Int.=laser interaction time)

\begin{tabular}{|c|c|c|c|c|}
\hline $\begin{array}{l}\text { Test/ } \\
\text { Spec. }\end{array}$ & $\begin{array}{l}\text { Material } \\
\text { Composi- } \\
\text { tion }\end{array}$ & $\begin{array}{l}\text { Precon- } \\
\text { ditioning }\end{array}$ & $\begin{array}{r}\text { Las. } \\
\text { Int. } \\
(\mathrm{s})\end{array}$ & $\begin{array}{r}\text { Age } \\
\text { (days) }\end{array}$ \\
\hline $\mathrm{LCS}_{40}$ & Limestone & Saturated & 40 & 114 \\
\hline $\operatorname{LCS}_{10 a}$ & Concrete & Saturated & 10 & 115 \\
\hline $\mathrm{LCS}_{10 b}$ & & Saturated & 10 & 115 \\
\hline $\mathrm{LCA}_{40}$ & & Air dried & 40 & 113 \\
\hline $\mathrm{BCS}_{40}$ & Basalt & Saturated & 40 & 114 \\
\hline $\mathrm{BCS}_{10 a}$ & Concrete & Saturated & 10 & 115 \\
\hline $\mathrm{BCS}_{10 b}$ & & Saturated & 10 & 115 \\
\hline $\mathrm{BCA}_{40}$ & & Air dried & 40 & 113 \\
\hline $\mathrm{MS}_{40}$ & Mortar & Saturated & 40 & 100 \\
\hline $\mathrm{MS}_{10 a}$ & & Saturated & 10 & 101 \\
\hline $\mathrm{MS}_{10 b}$ & & Saturated & 10 & 101 \\
\hline $\mathrm{MA}_{40}$ & & Air dried & 40 & 99 \\
\hline $\mathrm{PS}_{40}$ & $\mathrm{PFA}+\mathrm{OPC}$ & Saturated & 40 & 100 \\
\hline $\mathrm{PS}_{10 a}$ & Paste & Saturated & 10 & 101 \\
\hline $\mathrm{PS}_{10 b}$ & & Saturated & 10 & 101 \\
\hline $\mathrm{PA}_{40}$ & & Air dried & 40 & 99 \\
\hline $\mathrm{OS}_{40}$ & OPC & Saturated & 40 & 100 \\
\hline $\mathrm{OS}_{10 a}$ & Paste & Saturated & 10 & 101 \\
\hline $\mathrm{OS}_{10 b}$ & & Saturated & 10 & 101 \\
\hline $\mathrm{OA}_{40}$ & & Air dried & 40 & 99 \\
\hline $\mathrm{BRA}_{40}$ & Basalt & Air dried & 40 & - \\
\hline $\mathrm{LRA}_{40}$ & Limestone & Air dried & 40 & - \\
\hline
\end{tabular}

equates to $36 \mathrm{~s}$. Two interaction times were applied in this study: 10 s and 40 s.

\subsection{Data Acquisition and Analysis}

A 3D scanner (Geomagic Faro ScanArm 3D scanner) was used to detect the surface profile of scabbled specimens. A plane representing the original specimen surface was made in the Geomagic Studio software using three points on the surface that were unaffected by scabbling. The volume between the scanned profile and the original specimen surface was calculated using the 'volume to a plane' function in the software; this value has been used as the volume removal due to scabbling.

Density of the different compositions was determined using BS EN12390-7:2009 [25]. Porosity, moisture content and degree of saturation were subsequently determined using values found during the density tests. Porosity was defined as $100 *\left(\left(m_{\text {sat }}-m_{o d}\right) /\left(m_{\text {sat }}-m_{\text {sub }}\right)\right)$, where $m_{\text {sat }}, m_{\text {od }}$ and $m_{\text {sub }}$ are saturated, oven-dried and submerged masses. The moisture content was defined as $100 *\left(\left(m_{t}-m_{o d}\right) / m_{t}\right)$, where $m_{t}$ was the mass of the specimens before the tests. The degree of saturation was defined as $100 *\left(\left(m_{t}-m_{o d}\right) /\left(m_{\text {sat }}-m_{o d}\right)\right)$.

The chemical composition of all tested materials was
Table 3: Specimen properties $(\mathrm{MC}=$ moisture content, $\mathrm{SR}=$ degree of saturation, Em.=emissivity).

\begin{tabular}{lrrrrr}
\hline Spec. & $\begin{array}{r}\text { Porosity } \\
\%\end{array}$ & $\begin{array}{r}\text { MC } \\
\%\end{array}$ & $\begin{array}{r}\text { SR } \\
\%\end{array}$ & $\begin{array}{r}\text { Density } \\
\mathrm{kg} / \mathrm{cm}^{3}\end{array}$ & Em. \\
\hline \hline LCS & 11.07 & 4.57 & 99 & 2385 & 0.966 \\
LCA & 10.76 & 3.02 & 67 & 2395 & \\
BCS & 11.60 & 4.53 & 98 & 2518 & 0.978 \\
BCA & 11.27 & 3.20 & 71 & 2500 & \\
MS & 22.19 & 9.73 & 98 & 2223 & 0.990 \\
MA & 22.44 & 7.98 & 77 & 2186 & \\
PS & 43.49 & 21.90 & 96 & 1902 & 0.978 \\
PA & 42.08 & 18.16 & 80 & 1828 & \\
OS & 38.44 & 19.76 & 100 & 1996 & 0.941 \\
OA & 39.52 & 14.86 & 70 & 1868 & \\
BRA & 0.20 & 0.1 & - & 3006 & 0.941 \\
LRA & 7.37 & 0.1 & - & 2465 & 0.938 \\
\hline
\end{tabular}

determined by using X-ray fluorescence (XRF) and Xray diffraction (XRD). XRF analysis was performed using Panalytical Minipal 4 EDXRF benchtop, and XRD analysis was performed with a Siemens D5000 X-Ray diffractometer, using copper $\mathrm{K}-\alpha$ radiation. To characterise thermal processes taking place in specimens at elevated temperatures differential thermal and thermogravimetric analyses (DTA/TGA) were carried out using a Perkin Elmer Star 8000 simultaneous thermal analyser up to $1500^{\circ} \mathrm{C}$ in air, with aluminium oxide pan, aluminium oxide reference material and heat rate of $10^{\circ} \mathrm{C} /$ minute. The samples used in XRF, XRD and DTA/TGA were produced by breaking the control specimens, crushing the fragments and grinding the material (using pestle and mortar) until all material passed a $53 \mu \mathrm{m}$ sieve. Due to heterogeneity of the two concrete mixes, the small samples were not representative for the material as a whole and therefore the DTA/TGA, XRD and XRF results of these compositions should be taken with reserve.

The scabbling process in the tests was monitored by recording thermal images of the surface using a FLIR SC 640 infrared camera. The transmission of the infra red window used to protect the camera from debris and the emissivities of specimens were determined experimentally and used in the analysis of infrared data, carried out by using a software package ThermaCam Researcher Professional 2.8 SR-3 (FLIR Systems, Inc). In order to record the entire temperature range over a 10s interaction time, two experiments were conducted on separate (nominally identical) specimens of each material, using two different camera ranges: $0-550^{\circ} \mathrm{C}$ and $200-2000^{\circ} \mathrm{C}$. The thermal images were acquired at a time step $\Delta \mathrm{t}=(1 / 30) \mathrm{s}$. 


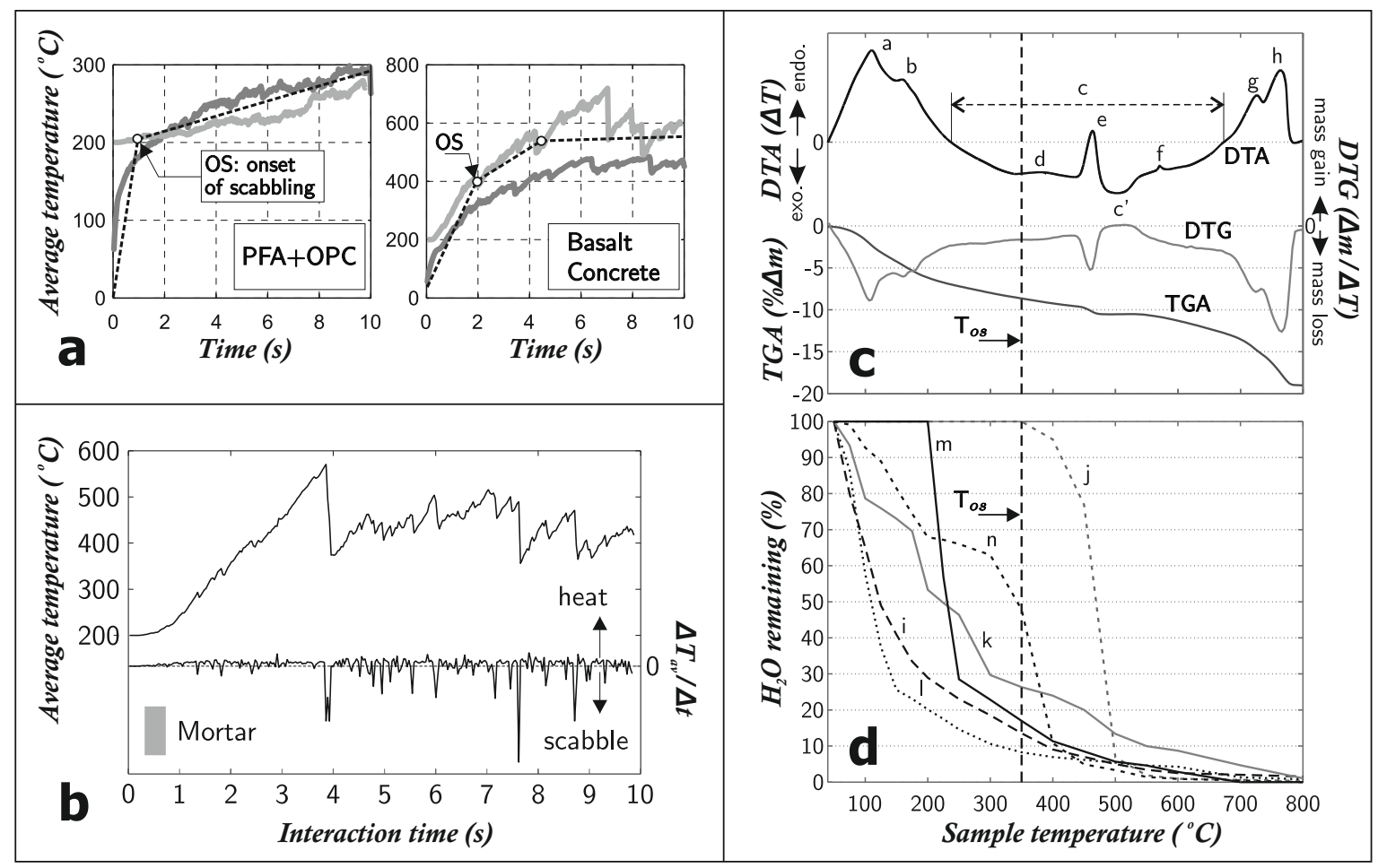

Figure 1: (a) Examples of how the onset of scabbling was detected, (b) time histories of average temperature and average temperature rate $\left(\Delta T_{a v} / \Delta t\right)$ for the mortar specimen, (c) Graphical representation of differential thermal analysis (DTA), thermo-gravimetric analysis (TGA) and the first differential of the thermo-gravimetric analysis (DTG), thermal reactions ' $a-h$ ' are decribed in Table 4, and (d) moisture ( $\mathrm{H}_{2} \mathrm{O}$ ) loss from cement phases, 'i-n' presented in Table 4 (taken from TGA data in literature [24]).

Emissivity of the specimens was calculated using the reference emissivity material method suggested by ISO 18434-1 [26]. Specimens were partially coated in scotch electrical tape (of known emissivity 0.97) and then heated to around $80^{\circ} \mathrm{C}$. The temperatures of the taped and untaped areas were compared and the emissivity of the specimens calculated.

All thermal images from the tests with 10 s laser interaction were processed to produce surface temperature histories. Two types of temperature histories were used in the analysis of test data: average and maximum surface temperatures of the heat affected zone (HAZ). The HAZ was defined as the surface area that exceeded $100^{\circ} \mathrm{C}$ after $1.0 \mathrm{~s}$ of interaction time. The time histories of maximum temperature were obtained by identifying the maximum temperature in each frame, regardless of it's location in the HAZ. Infrared results reported here are for saturated specimens only.

The time histories of maximum surface temperature were only used to assess the reliability of the average surface temperature data. The time histories of average surface temperature, showing the temperature fluctuations due to ejection of fragments (their amplitudes corresponding to size of fragments), were used as key data in characterisation of the scabbling behaviour of each material. Temperatures and times at the onset of scabbling ( $T_{o s}$ and $\left.t_{o s}\right)$, pre-scabbling heating rates, as well as heating rates and temperature fluctuations during scabbling were identified from trends in the time histories of average surface temperatures for each test (Figure 1.a). The frequency and amplitudes of surface temperature fluctuations were used to quantify the frequency of ejections and size of the fragments (Figure 1.b).

The temperature at the onset of scabbling $\left(T_{o s}\right)$ for each material was then compared with DTA/TGA results of the corresponding composition. Thermal reactions that took place prior to the temperature at the onset of scabbling were identified (Figure 1.c). Data on water loss from cement phases taken from TGA results found in literature [24] (heat rate of $10^{\circ} \mathrm{C} / \mathrm{min}, 50 \mathrm{mg}$ sample size, in nitrogen with flow rate $15 \mathrm{ml} / \mathrm{min}$ ) was used in conjunction with the temperature at the onset of scabbling to indicate the extent of cement phase decomposition at the onset temperatures (Figure 1.d).

In parallel with the infrared camera, a high-speed 
camera (Phantom V5.1) was used to record the ejection of fragments. At this (initial) stage of the programme, the high-speed camera data was used only to provide qualitative information about the scabbling frequency and size of ejected fragments, This was compared with the data obtained in the analysis of the fluctuations in temperature histories. All debris was collected after each test, but it could not be used for analysis of fragment sizes as ejected fragments were further fractured upon impact with the walls of the chamber.

\section{Test Results}

\subsection{Vitrification}

Figure 2 shows the specimens after 40s laser interaction time [27]. It can clearly be seen that all cement and concrete specimens underwent varying degrees of surface removal. Vitrification was identified in basalt rock specimens (BRA) and concrete specimens with basalt coarse aggregate (BCA and BCS). Vitrification was more prominent in saturated than air dried specimens. Slight vitrification can be seen in the mortar of the limestone concrete specimens (LCA and LCS). The saturated OPC paste (OS) showed a large extent of vitrification (approximately $75 \%$ of scabbled area), whereas the saturated PFA+OPC (PS) paste showed only small amounts of vitrification on the periphery of the scabbled area $(<10 \%)$. The air dried cement pastes (PA and OA) and both mortar specimens (MA and MS) did not show any evidence of vitrification. The experimental set up, whereby ejected debris was able to fall back onto the specimen to receive further laser interaction, increases vitrification. This would be avoided in normal applications where the vacuum would remove any debris.

\subsection{Volume Removal}

The trough profiles of the OPC cement paste (OA, OS) were much shallower than those of the PFA+OPC (PS, PA) specimens (Figure 3). The air dried PFA+OPC paste (OS) showed a two tiered profile, where the deeper centre had a diameter approximately equal to that of the beam diameter. The trough profiles of the air dried mortar specimen (MA) has a similar depth to the corresponding $\mathrm{PFA}+\mathrm{OPC}$ (PA) profile, but is wider. The comparison of saturated mortar (MS) and PFA+OPC paste (PS), shows a deeper and narrower profile for the PS (Figure 3). The comparison of the concretes show similar profiles for the air dried basalt concrete (BCA) and the two limestone concretes (LCA, LCS), but a shallower profile for saturated basalt concrete (BCS).

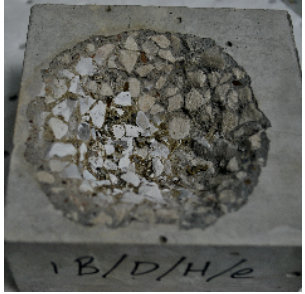

LCA

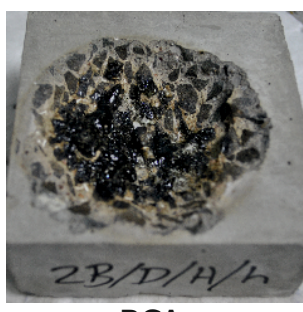

BCA

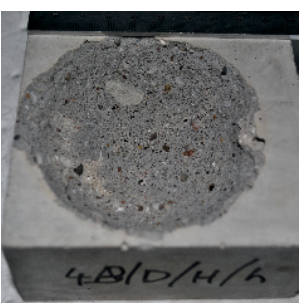

MA

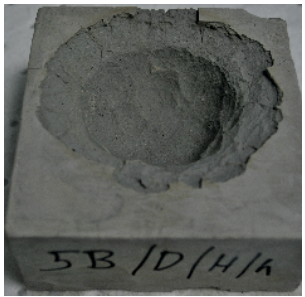

$\mathrm{PA}$

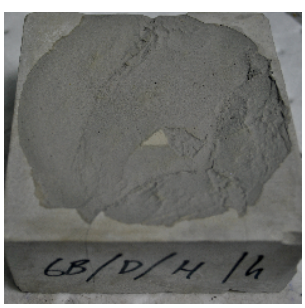

$\mathrm{OA}$

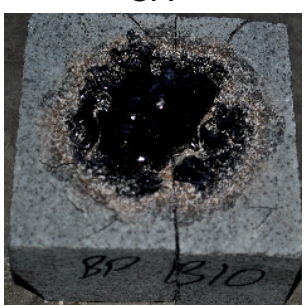

BRA

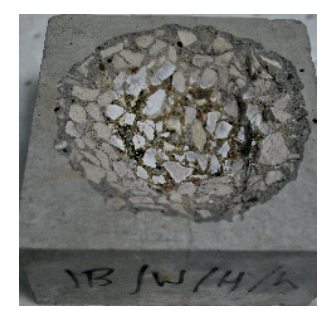

LCS

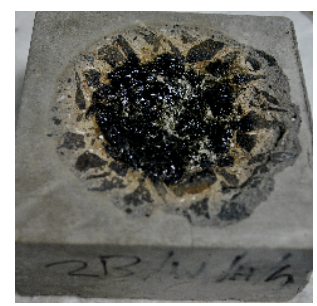

BCS

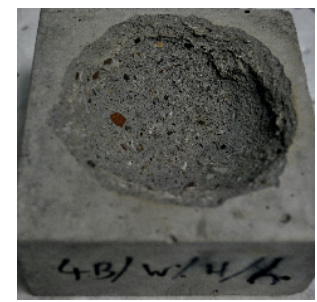

MS

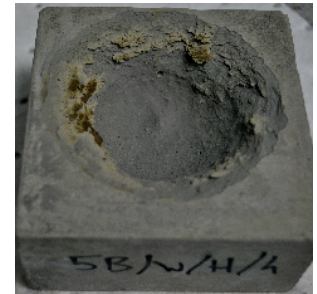

PS

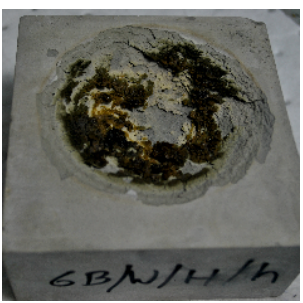

OS

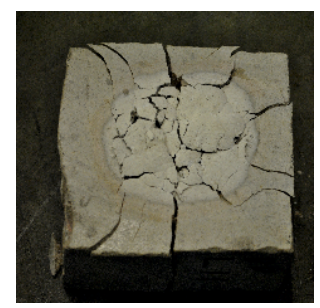

LRA
Figure 2: Photos of specimens of all compositions after 40s of laser interaction [27]. 

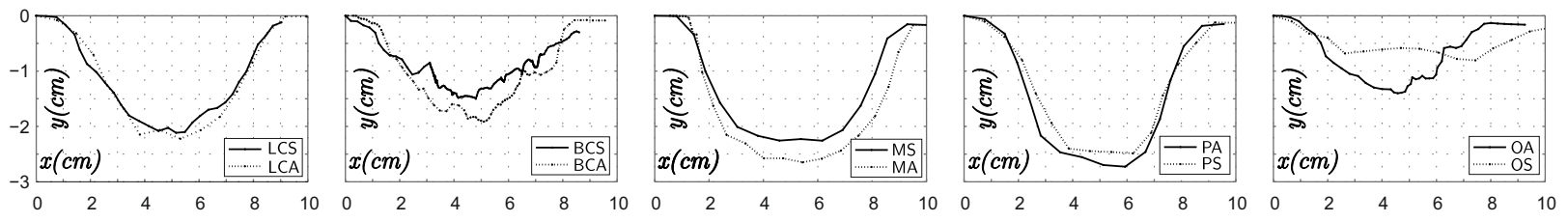

Figure 3: Centre line trough profiles of specimens of all compositions after 40s of laser interaction.

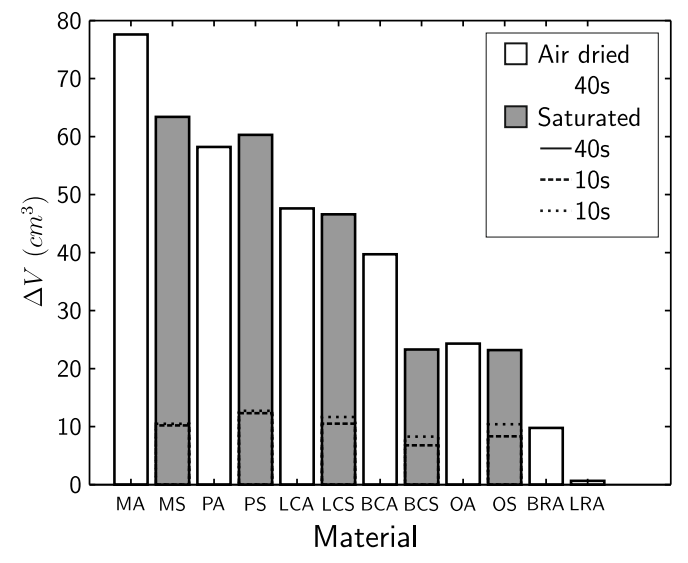

Figure 4: Volume removal after 10 s and 40 s of laser interaction.

Results presented in Figure 4 show the volume removal of each of the compositions when exposed to $10 \mathrm{~s}$ and $40 \mathrm{~s}$ of $4.76 \mathrm{~kW}$ stationary laser beam of $60 \mathrm{~mm}$ nominal diameter. It can clearly be seen that mortar specimens (MA, MS) have the largest volume removal followed by PFA+OPC paste (PA, PS), limestone concrete (LCA, LCS), basalt concrete (BCS, BCA), OPC paste (OA, OS) and finally basalt rock specimen (BRA), while the limestone rock (LRA) experienced no notable volume loss. The large level of vitrification of the saturated OPC paste compared to the PFA+OPC paste is due to the lower volume removal experienced in the OPC paste.

The effect of the two types of preconditioning on volume removal was variable (Figure 4). Small variations in volume removal between the saturated and air dried specimens can be seen for the limestone concrete (LCA, LCS), PFA+OPC (PA, PS) and OPC compositions (OA, OS). Saturated specimens of basalt concrete (BCS) and mortar (MS) experienced lower volume removal compared to the corresponding air dried specimens (BCA, MA). In the case of saturated basalt concrete, part of the reduction in total volume removal (in BCS) compared with the air dried basalt concrete (BCA) could be a result of the larger extent of vitrification (Figure 2). However, the increased vitrification of the saturated pastes
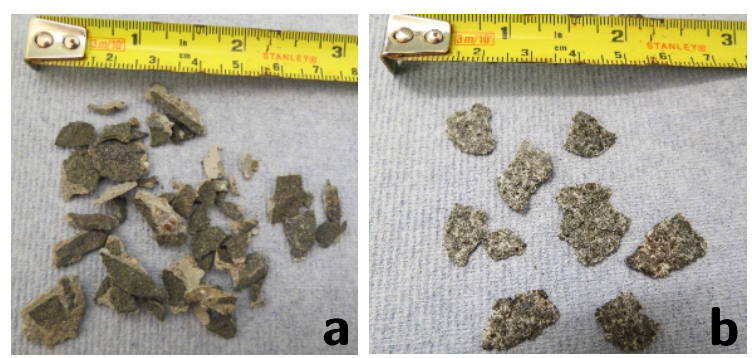

Figure 5: Debris of basalt concrete specimens: (a) saturated (BCS) and (b) air dried (BCA) [27].

(OS, PS) compared to the air dried pastes (OA, PA), did not coincide with differences in volume removal between the saturated pastes. The degree of saturation also affected the size of debris, which was smaller for saturated specimens, regardless of composition.

Solid rock specimens showed very different behaviour from that of the corresponding concrete specimens. The limestone rock specimen exhibited very little volume removal, with small fragments ejected in the first few seconds. The end result of laser application were remnants of a white powder on the surface: calcium oxide, the product of calcium carbonate decarbonation [8], also identified in the limestone concrete specimens (LCA, LCS). The basalt rock specimen showed some scabbling of thin flakes (Figure 5.b), but by the end of 40s interaction time the specimen had undergone large scale vitrification. Both limestone and basalt rock specimens exposed to 40s laser interaction times underwent extensive fracture after cooling (Figure 2). This was not experienced in the concrete, mortar or cement paste specimens.

\subsection{Specimen Properties}

Porosity, moisture content, degree of saturation and density of the different materials (Table 3 ) were determined to identify potential causes for the differences in scabbling behaviour. A greater cement paste content (cement pastes $>$ mortar $>$ concretes as seen in Table 1) resulted in higher moisture content, higher porosity and 


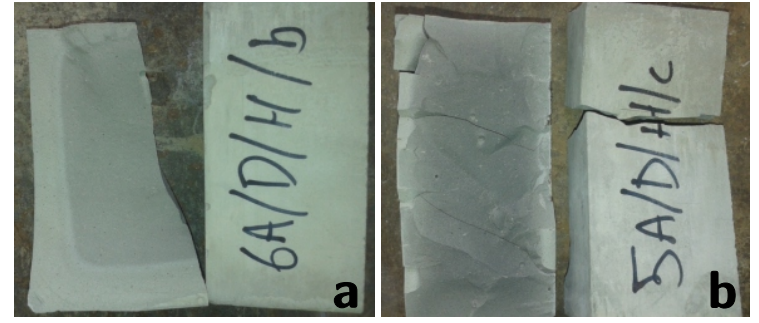

Figure 6: Cross sections of air dried cement paste specimens; (a) OPC and (b) PFA+OPC.

lower density. The higher porosity of PFA+OPC, compared to the OPC paste, is a result of the increase in water/cement ratio, due to the constant water/binder ratio in the two mixes (Table 1). Rock specimens had the highest density, lowest porosity and lowest moisture content. Limestone concrete has a slightly lower porosity than the basalt concrete, despite the porosity of limestone rock being an order of magnitude greater than that of the basalt rock. This could be caused by two factors: (i) the limestone rock absorbing more water from the concrete mix and reducing the effective water/cement ratio in the paste, and (ii) the volume of cement paste was larger for the basalt concrete, as the two concrete mixes have the same mass of coarse aggregates, but the density of basalt is higher than that of limestone.

The air dried concrete specimens experienced approximately $30 \%$ reduction in moisture content compared to the saturated specimens, the mortar and PFA+OPC specimens had approximately a $20 \%$ reduction and the OPC cement paste a $25 \%$ reduction. This difference in moisture content reduction is illustrated in Figure 6 which shows the extent of drying which took place in the air dried cement paste specimens after 50 days of preconditioning, exposed to identical conditions. It can be seen that air dried specimens did not have a uniform moisture content distribution, but a dry surface and a saturated core. The depth of drying was greater in the OPC specimen $(8-12 \mathrm{~mm})$ compared to the PFA+OPC specimen (1-5mm), indicating lower permeability of the PFA+OPC paste.

\subsection{Surface Temperature Histories}

Time histories of average surface temperature (Figure 7.a) show reasonable repeatability in the two (nominally identical) tests in which the thermal images were recorded with two different camera settings. The largest difference recorded for basalt concrete specimens is because this material was heated to temperatures higher than $550^{\circ} \mathrm{C}$ (Figure 7.b), which could not be recorded in the first test. Combining the results of the two tests shows that all specimens exhibit bi-linear or tri-linear behaviour (Figure 7.a), which allows detection of the onset of scabbling (illustrated in Figure 7.c).

All materials have similar initial heating rates of about about $200^{\circ} \mathrm{C} / \mathrm{s}$. The onset of scabbling for the two cement pastes can be identified at about $200^{\circ} \mathrm{C}$ $\left(\mathrm{t}_{o s}=1 \mathrm{~s}\right)$, after which they exhibit an almost constant, reduced heating rate of $10-12^{\circ} \mathrm{C} / \mathrm{s}$ for the rest of the test. The initial heating rate for limestone concrete and mortar is reduced between $200^{\circ} \mathrm{C}$ and $350^{\circ} \mathrm{C}$, a range in which small temperature fluctuations indicate scabbling of small fragments. At about $350^{\circ} \mathrm{C}$ temperature fluctuations become larger, heating rate drops to $0^{\circ} \mathrm{C} / \mathrm{s}$, and this temperature can be identified as the onset of scabbling for these two materials. Basalt concrete shows somewhat different, tri-linear behaviour, with an extended range of the initial heating rate to about $400^{\circ} \mathrm{C}$, followed by a reduced rate (about $100^{\circ} \mathrm{C} / \mathrm{s}$ ) to $550^{\circ} \mathrm{C}$, a range during which there are some significant temperature fluctuations, and then a plateau $\left(0^{\circ} \mathrm{C} / \mathrm{s}\right)$ characterised with large fluctuations. Hence the onset of scabbling for basalt concrete can be identified at $400^{\circ} \mathrm{C}$, and the post scabbling behaviour described as a twostage process. The values of temperature $\left(\mathrm{T}_{o s}\right)$ and time $\left(\mathrm{t}_{o s}\right)$ at the onset of scabbling for all materials are summarised in Table 4.a.

\subsection{Scabbling Frequency and Fragment Sizes}

When a fragment is ejected during the scabbling process, the temperature of the exposed surface is lower than that recorded in the preceding frame (Figure 8.a). Hence scabbling of a larger fragment would result in a larger temperature drop (negative $\Delta T / \Delta t$ rate), followed by a period of temperature increase until the next fragment ejection (positive $\Delta T / \Delta t$ rate).

The frequency and size of negative temperature rate values in the time history of average surface temperatures $(\Delta T / \Delta t$, where $\Delta t=0.033 \mathrm{~s})$ was used to identify the frequency and scale of scabbling (Figure 8). Here frequency is defined as number of negative fluctuations $\left(N_{f}\right)$ of a different magnitude $(\Delta T$, in steps of $2^{\circ} \mathrm{C}$ ), recorded during the laser interaction period $(10 \mathrm{~s}$, with step $\Delta t=0.033 \mathrm{~s})$. The higher frequency of smaller $\Delta T / \Delta t$ fluctuations $\left(0-4^{\circ} \mathrm{C} / \Delta t\right)$ for the cement paste specimens indicates smaller fragment sizes of these compositions when compared to mortar or concrete specimens, which experience a higher frequency of larger temperature fluctuations (above $10^{\circ} \mathrm{C} / \Delta t$ ). The largest temperature fluctuations (over $100^{\circ} \mathrm{C} / \Delta t$ ) were recorded for basalt and mortar specimens, suggesting the largest fragment size. The results also show that, compared to the OPC paste, the PFA+OPC scabbling 

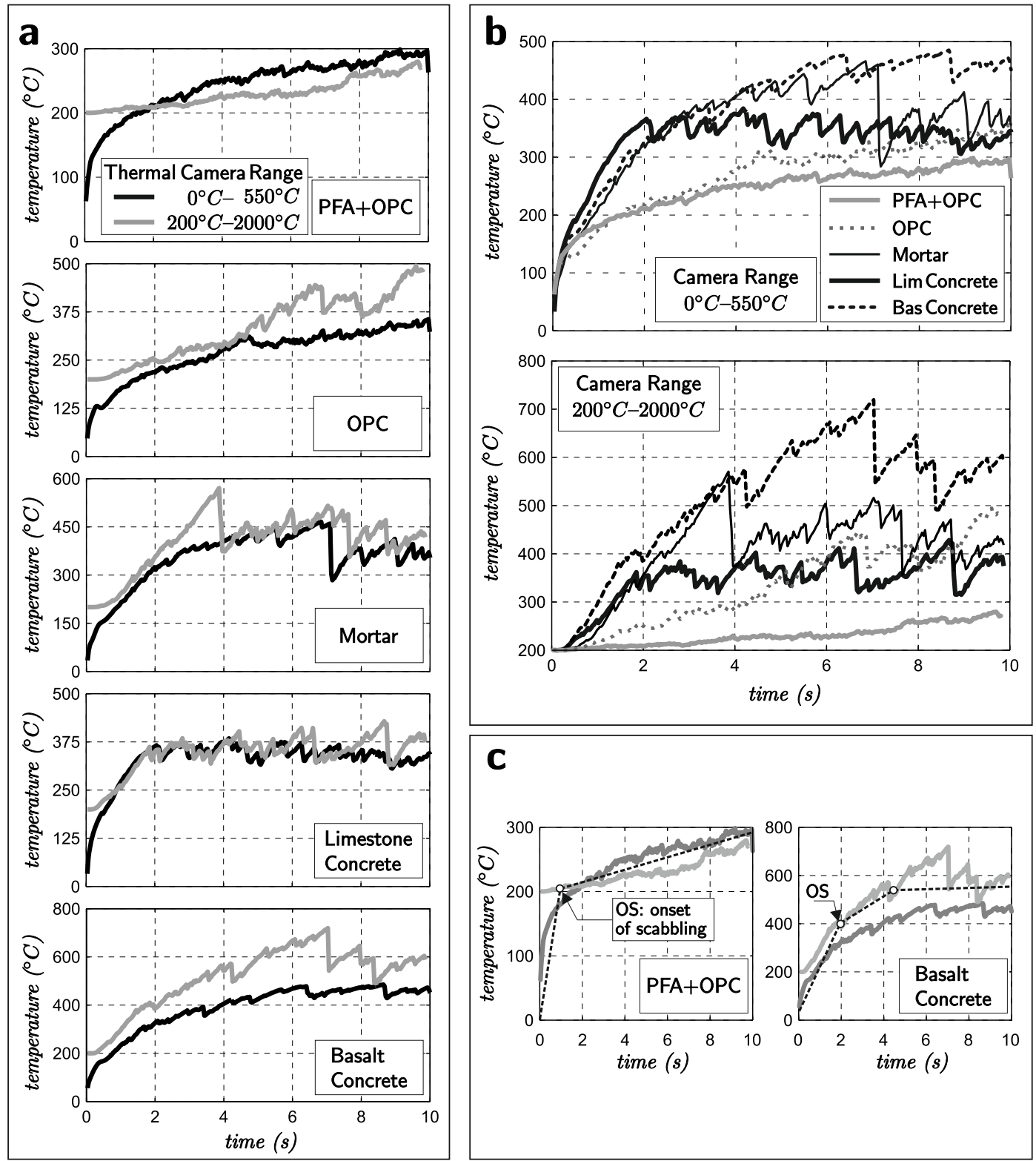

C
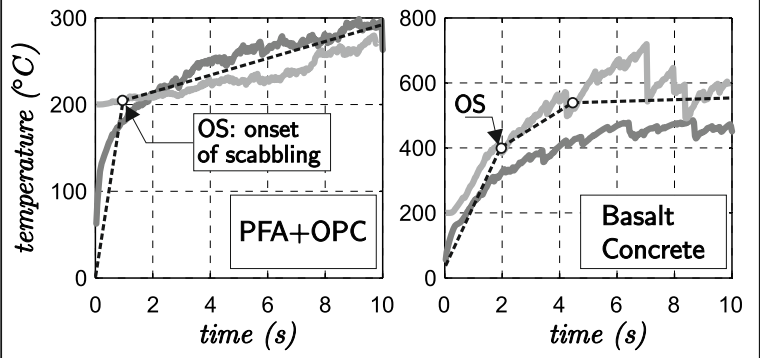

Figure 7: Time histories of average surface temperatures: (a) histories for each material (saturated) recorded in two tests using two different thermal camera settings, (b) comparison of scabbling behaviour of all materials recorded in the two tests, and (c) detection of phases in scabbling behaviour: onset of scabbling and onset of steady state phase 


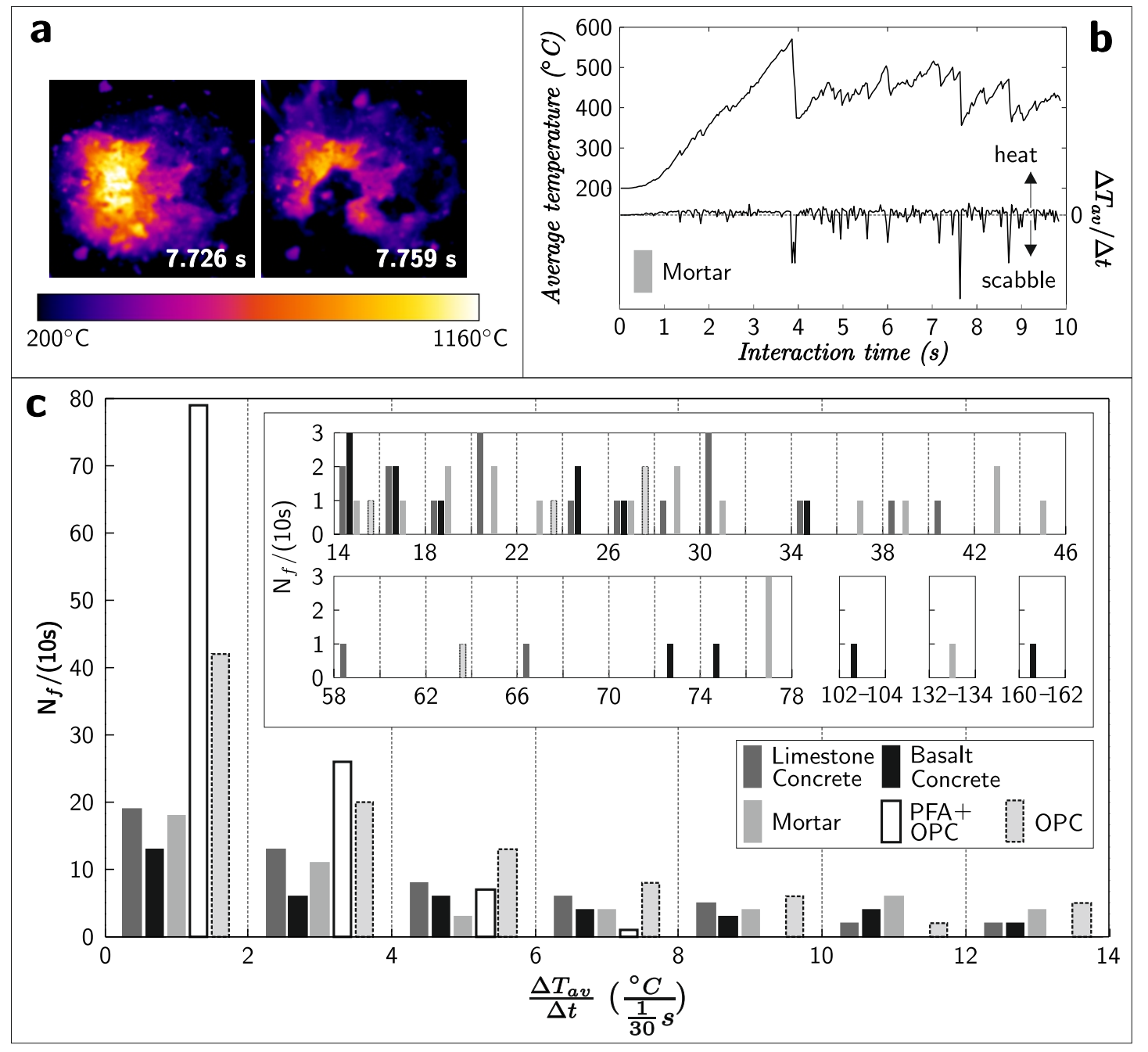

Figure 8: Frequency distribution of average surface temperature drops (over a $0.033 \mathrm{~s}$ interval) for each composition. (a) infrared images before and after a large temperature fluctuation for the mortar specimen, (b) time histories of average temperature and average temperature rate ( $\left.\Delta T_{a v} / \Delta t\right)$ for the mortar specimen, (c) distribution of temperature drops recorded during 10 s interaction time for all materials 
was characterised by a larger number of very small fluctuations $\left(<2^{\circ} \mathrm{C} / \Delta t\right)$, as well as a complete absence of larger fluctuations $\left(>8^{\circ} \mathrm{C} / \Delta t\right)$, suggesting smaller fragment sizes. These results were confirmed by the analysis of thermal and high-speed camera images.

\subsection{Thermal Reactions}

The temperatures at the onset of scabbling were combined with DTA/TGA results for all paste, mortar and concrete compositions, to determine which thermal reactions took place before and after the onset of laser scabbling. It should be noted that the heat rate affects the extent to which thermal reactions take place. For example, when higher rates were used the complete thermal decomposition of cement phases occurred at higher temperatures [28, 29]. This means that the results from combining the temperature at the onset of scabbling (heat rates of $175-200^{\circ} \mathrm{C} / \mathrm{s}$ ) with DTA/TGA results (heat rate $10^{\circ} \mathrm{C} / \mathrm{min}$ ) should be used only qualitatively. This method is suitable for detecting reactions that may take place (although to a lesser extent than that shown by the DTA/TGA) and eliminating thermal reactions that occur at higher temperatures.

DTA/TGA results, illustrated for the mortar specimen in Figure 1.c and presented for all compositions in Table 4.b, identify the thermal reactions that would take place in concrete/cement specimens prior to reaching the onset of scabbling (values in bold). A large endothermic peak and mass loss (peak ' $a$ ' in Table 4.b) between $90-120^{\circ} \mathrm{C}$, for all compositions, is due to evaporation of free and interlayer water [30, 31, 32, 33, 34]. A smaller endothermic peak and mass loss ('b') was identified between $130-190^{\circ} \mathrm{C}$ in all samples as a result of decomposition of cement phases. Less pronounced peaks at 'b' are seen for samples with a lower cement paste content. A doublet in this region ('b') was present only in the PFA+OPC paste. Lilkov [35] and Odler [36], who investigated OPC-PFA mixes, suggested similar peaks to be due to thermal decomposition of calcium monosulfoaluminate, with decomposition of calciumhydrocarboaluminate as a less likely option [35]. These two thermal reactions (' $a$ ' and ' $b$ ') occur in DTA tests at temperatures below the onset of scabbling for all compositions.

Mortar and PFA+OPC paste samples show exothermic behaviour ('c') between $238-677^{\circ} \mathrm{C}$, with slight mass increases ('c') around $500^{\circ} \mathrm{C}$, most likely due to oxidation of metallic impurities present in PFA. The lower range of this reaction is below $350^{\circ} \mathrm{C}$, the onset temperature of mortar, but above the onset of the $\mathrm{PFA}+\mathrm{OPC}$ paste $\left(200^{\circ} \mathrm{C}\right)$. The absence of PFA in OPC pastes or its reduced proportion in the mass of concrete samples explains why this process is not observed in the DTA/TGA results for these compositions.

A wide endothermic hump and slight mass loss (' $\mathrm{d}$ ') due to dehydration of hydration products such as calcium hydrosilicates, calcium hydroaluminates and ettringite [35] was present around $340-440^{\circ} \mathrm{C}$ in mortar, PFA+OPC and OPC samples. Mortar is the only composition where this reaction occurs below the temperature at the onset of scabbling. An endothermic peak and mass loss ('e') due to portlandite (calcium hydroxide) dehydroxylation $[34,37,38,39,40]$ was observed in all samples between $430-510^{\circ} \mathrm{C}$. This reaction occurs below the temperature of the onset of scabbling only for the basalt concrete.

An endothermic peak at $572{ }^{\circ} \mathrm{C}$ ('f') occurs with no mass loss due to the $\alpha$-quartz to $\beta$-quartz inversion [4, 33 ], most prominent in specimens with the largest sand content. The change in crystal structure gives rise to a $0.85 \%$ volume expansion [41]. The inversion is present in all specimens except the OPC paste, but only below the temperature of onset for the basalt concrete.

Decarbonation of calcium carbonate phases vaterite ('g') and calcite (' $h$ ') at around $650-850^{\circ} \mathrm{C}[4,31,33$, 34] are identified above the temperature of onset for all samples.

Table 4.c shows the percentage of water loss in specific cement phases (taken from literature [24]) at the onset of scabbling temperatures for each of the compositions. This is illustrated for the mortar specimen in Figure 1.d. These results have been recorded at a heat rate of $10^{\circ} \mathrm{C} / \mathrm{min}$. The actual dehydration could be much lower at the onset temperatures (Tos), where the heat rates were of up to $1200^{\circ} \mathrm{C} / \mathrm{min}$. In the absence of test data recorded at high heat rates, the values shown in the table can only be used as indication that: (i) some dehydration of all cement phases would take place below Tos $=400^{\circ} \mathrm{C}$ (basalt concrete); (ii) in limestone concrete and mortar $\left(\operatorname{Tos}=350^{\circ} \mathrm{C}\right)$, some dehydration will be expected in all phases with the exception of portlandite (e in Figure 1.c or $\mathrm{j}$ in Figure 1.d); (iii) very little dehydration would occur in cement pastes before the onset of scabbling $\left(\mathrm{Tos}=200^{\circ} \mathrm{C}\right.$ ) although some of the water from the calcium silicate hydrate $(\mathrm{C}-\mathrm{S}-\mathrm{H})$ phase may have been released. The cement phase decomposition would continue after the onset of scabbling as surface temperatures increase with the increase of interaction time.

\subsection{Chemical Composition}

XRF data (Table 5) shows that OPC replacement with PFA increases silicon (silica) and aluminium (alumina) content while decreasing calcium (calcium oxide, lime) 
Table 4: (A) Temperature, time and heat rate at onset of scabbling, (B) DTA/TGA results: temperature and mass change of thermal reactions in each composition (* due to heterogeneity of concrete mixes, small samples are not representative; results to be taken with reserve.), (C) $\mathrm{H}_{2} \mathrm{O}$ loss from cement phases at onset temperatures (TGA results taken from Taylor [24]).

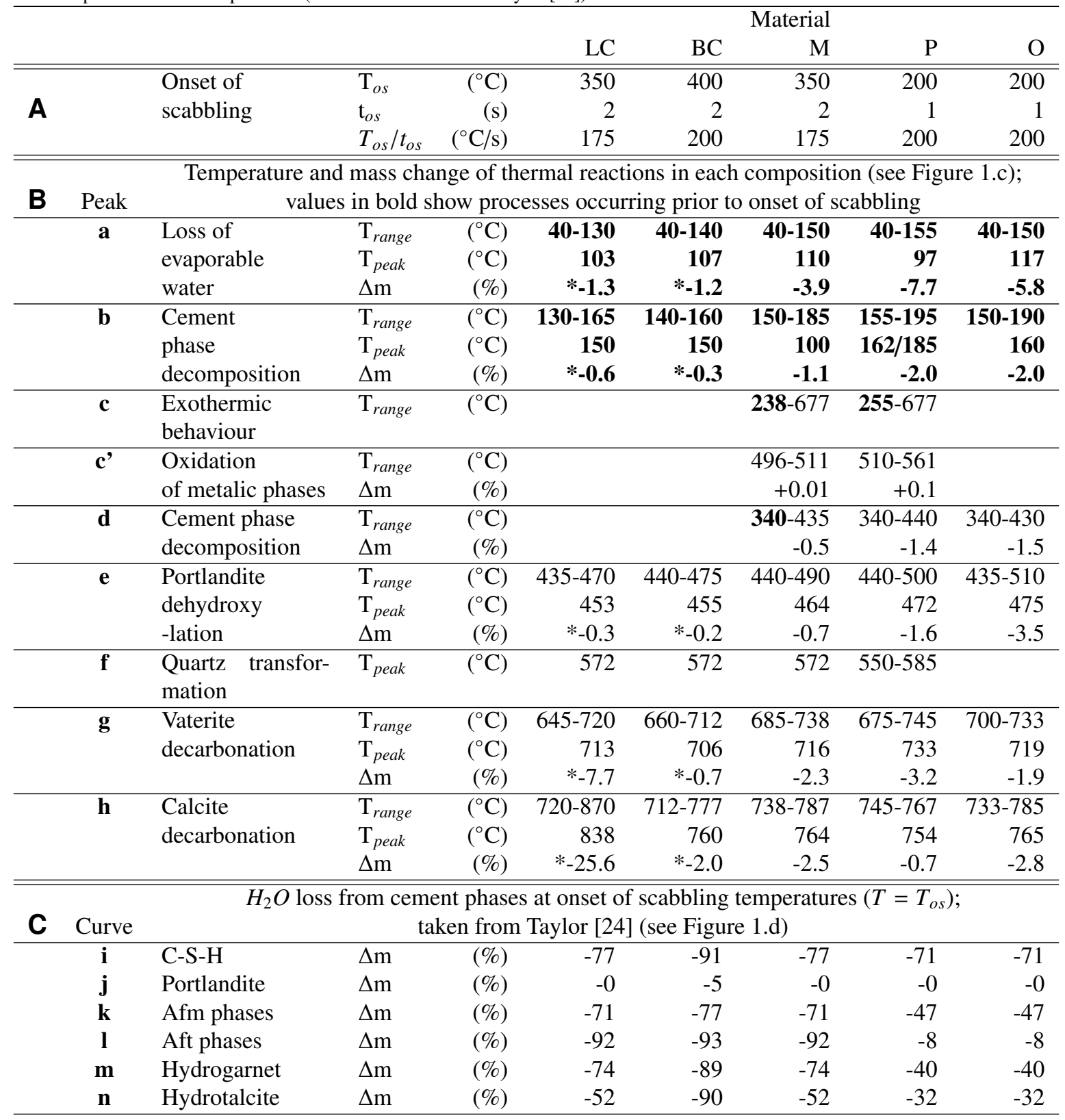


Table 5: Results of XRF analysis: chemical composition (\% atomic mass) of specimens ( $\mathrm{LC}=$ limestone concrete, $\mathrm{BC}=$ basalt concrete, $\mathrm{M}=\mathrm{mortar}$, $\mathrm{P}=\mathrm{PFA}+\mathrm{OPC}$ paste, $\mathrm{O}=\mathrm{OPC}$ paste) and constituents (Bas.=basalt aggregate, Lime.=Limestone aggregate). XRF equipment used does not identify elements with atomic number lower than, therefore values presented do not add up to $100 \%$.

\begin{tabular}{lrrrrrrrrrr}
\hline & \multicolumn{4}{c}{ Constituents } & \multicolumn{6}{c}{ Specimens } \\
& OPC & PFA & Sand & Bas. & Lime. & LC & BC & M & P & O \\
\hline \hline $\mathrm{Mg}$ & 1.32 & 0.76 & 0.41 & 2.72 & - & 0.32 & 1.76 & 0.18 & 0.56 & 0.26 \\
$\mathrm{Al}$ & 2.88 & 17.31 & 3.09 & 10.96 & 0.16 & 3.00 & 7.16 & 3.34 & 4.56 & 1.97 \\
$\mathrm{Si}$ & 9.82 & 33.26 & 51.95 & 33.24 & 0.23 & 23.07 & 32.31 & 31.28 & 12.17 & 7.81 \\
$\mathrm{P}$ & - & - & 0.13 & 0.38 & 0.04 & 0.24 & 0.24 & 0.22 & 0.24 & 0.22 \\
$\mathrm{SO}$ & 2.55 & 1.51 & 0.67 & 0.64 & - & 0.97 & 0.91 & 1.03 & 1.59 & 1.43 \\
$\mathrm{~K}$ & 0.94 & 4.81 & 1.56 & 1.33 & - & 1.02 & 1.29 & 1.20 & 1.39 & 1.59 \\
$\mathrm{Ca}$ & 59.96 & 2.69 & 9.17 & 10.05 & 72.04 & 68.47 & 14.29 & 19.87 & 42.00 & 50.02 \\
$\mathrm{Ti}$ & 0.23 & 1.07 & 0.21 & 2.03 & 0.02 & 0.28 & 1.28 & 0.22 & 0.42 & 0.20 \\
$\mathrm{Fe}$ & 2.27 & 10.71 & 1.97 & 13.81 & 0.04 & 2.61 & 9.31 & 2.26 & 4.13 & 2.11 \\
\hline
\end{tabular}

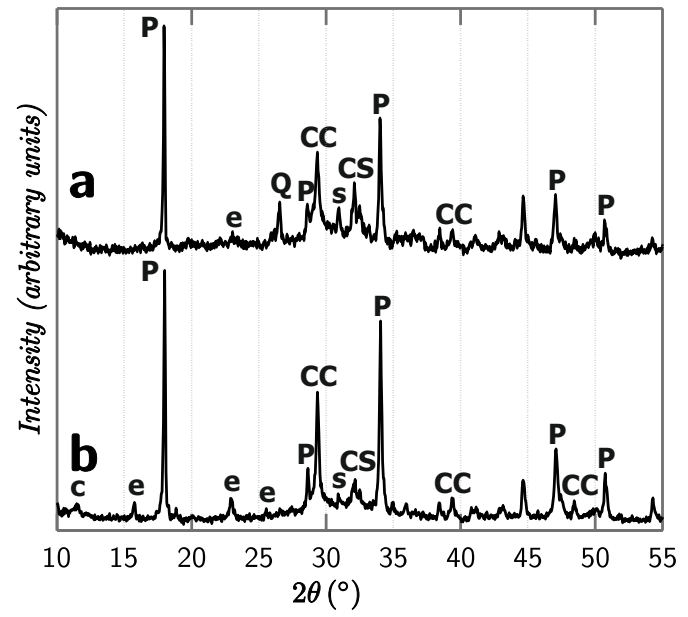

Figure 9: XRD spectra of a) PFA+OPC and b) OPC cement paste specimens. ( $\mathrm{e}=$ ettringite, $\mathrm{c}=$ monocarbonate, $\mathrm{P}=$ portlandite, $\mathrm{Q}=$ quartz, $\mathrm{CC}=$ calcium carbonate, $\mathrm{s}=$ monosulphate, $\mathrm{CS}=$ calcium silicate, $[42,43,44])$

content following the trend of the constituents. The high silicon content of sand means the mortar has the highest silica content followed by the basalt concrete, limestone concrete and the two cement pastes (PFA+OPC and $\mathrm{OPC}$ ).

Both XRD (Figures 9.a and 9.b) and DTA analyses (Table 4.b) identify the decreased portlandite content of the PFA+OPC compared to the OPC sample. Portlandite is a product of OPC hydration and therefore the OPC paste sample has the greatest content. OPC replacement with PFA reduces portlandite content in two ways, (i) by reducing OPC content and (ii) by using the portlandite as a reactant in the pozzolanic reaction. XRD results show an increased calcium silicate content in the PFA+OPC sample, potentially due to the poz- zolanic reaction. Calcium carbonate content is higher in the OPC due to carbonation of portlandite during specimen preparation, therefore a lower portlandite content will result in a lower calcium carbonate content [45]. The XRD spectrum for the OPC paste suggests there is more ettringite present in OPC compared with the PFA+OPC. Monosulphate seems to be present in higher proportions in the PFA+OPC specimen, whereas monocarbonate is more prominent in the OPC specimens. It is likely that these cement phases are responsible for the differences in reaction ' $b$ ' for the cement pastes in Table 4.b. Silica (quartz) is shown to be present in the PFA+OPC specimen due to unreacted silica from the PFA.

\section{Discussion of Results}

\subsection{Potential Mechanisms}

The results of explosive spalling studies, summarised by Khoury and Anderberg [14], suggest that explosive spalling is a result of one of two mechanisms. Pore pressure spalling is the process of steam retreating within the concrete where it condenses to form an impermeable saturated zone, which further restricts mass migration causing a build up of pore pressures. Permeability and moisture content are identified as key factors for this mechanism. Thermal stress spalling is caused by high heat rates and the low thermal conductivity of concrete inducing severe thermal gradients and subsequently differential thermal expansions that cause fracture. The two mechanisms work against each other. For example, a higher moisture content is likely to increase pore pressures but reduce thermal stresses due to the cooling effect caused by evaporation and increasing conductivity. 
It has been reported that a higher silica content increases the susceptibility of a concrete to explosively spall during fire conditions due to the crystal transformation that takes place in quartz at around $572^{\circ} \mathrm{C}$ $[13,46]$ (reaction 'f' in Table 4.b). This study and early studies on laser scabbling of concrete [7, 8, 9] found that the siliceous aggregates tested (granite and basalt) hindered the scabbling process, but limestone aggregate concrete scabbleed successfully. All specimens in this study underwent scabbling at temperatures below that of the quartz inversion, suggesting that this reaction is not necessary for scabbling to take place.

Thermal reactions detected in DTA/TGA results are likely to affect scabbling in a number of ways. Thermal decomposition reactions such as cement phase dehydration and calcium carbonate decarbonation, will release gases increasing pore pressures, but also weaken the structure reducing the stresses necessary for scabbling to take place. On the other hand, thermal decompositions and thermal mismatch between constituents will increase permeability, allowing dissipation of pore pressures, reducing scabbling.

The fact that mortar and PFA+OPC paste showed similar volume removals, while concrete specimens (with much reduced cement paste content) experienced lower volume removals and rock specimens almost no scabbling, suggests that the mechanism responsible for laser scabbling takes place within the cement matrix, where addition of fine aggregates introduces a secondary effect which increases debris size and slightly enhances volume removal.

The temperatures at the onset of scabbling vary between compositions. The two cement pastes have similar values $\left(200^{\circ} \mathrm{C}\right)$, with the mortar and concrete specimens having higher onset temperatures $\left(350-400^{\circ} \mathrm{C}\right)$. The results show that a higher cement paste content allows scabbling to take place at lower temperatures, further supporting the suggestion that the scabbling process takes place within the cement matrix. This could be due to more free, interlayer and chemically combined water being available to aid pore pressure spalling, and therefore a lower surface temperature is required to produce sufficient pressures.

All cement paste and concrete compositions underwent some degree of volume removal suggesting the stochastic behaviour reported in previous studies [7, 8, 9] was not detected in this study. Concrete age was not reported in previous studies, hence the young age of specimens used in this study (99-114 days) may be a determining factor.

\subsection{Scabbling of Cement Pastes: Effect of PFA Re- placement}

Results presented in this study show that the use of PFA as a cement replacement material enhances the volume removal of hardened cement paste during laser scabbling, suggesting a mortar or concrete without PFA (not tested here) would experience lower volume removals than a mortar or concrete with PFA replacement.

The PFA+OPC paste had a larger water/cement ratio when compared to OPC paste (Table 1). Water not chemically combined during hydration remains as free water which forms capillary pores [41], resulting in higher moisture content and higher porosity [47]. This increase in porosity is the cause of the lower density of the PFA+OPC cement paste and potentially of a reduced strength at the age of testing (99-114 days).

While PFA replacement increases total porosity [47], it has been reported that the larger proportion of foil like $\mathrm{C}-\mathrm{S}-\mathrm{H}$ produced by the pozzolanic reaction reduces pore connectivity and as a result permeability is reduced [24]. The reduced drying experienced by the air dried PFA+OPC specimen when compared to the air dried OPC specimen seen in Figure 6 supports this.

Use of PFA changes the chemical composition of the system causing different hydrates and phases to be formed. This in turn affects the thermal and mechanical properties of the material. The DTA/TGA results show a doublet between $155-195^{\circ} \mathrm{C}$ in the PFA+OPC sample, while the OPC specimen displays a plateau. This difference is most likely due to the different phases and/or different proportions of similar phases, as identified in Figure 9. This could also be the reason for the endothermic hump 'c' in DTA results (Table 4.b), which is more prominent in the PFA+OPC than the OPC sample.

The pozzolanic reaction and reduction in OPC content in the PFA+OPC paste will reduce the portlandite content compared to the OPC paste. This can be seen by the larger intensities of the portlandite peak in the XRD analysis (Figure 9) and the reduced mass loss due to portlandite dehydroxylation (' $\mathrm{e}$ ') in the TGA (Table 4.b). It can be seen from Table 4.c that C-S-H (i') decomposition begins prior to the temperature at the onset of scabbling $\left(200^{\circ} \mathrm{C}\right)$, whereas portlandite (e') does not undergo any dehydroxylation until around $400^{\circ} \mathrm{C}$. The replacement of portlandite with $\mathrm{C}-\mathrm{S}-\mathrm{H}$ that occurs during the pozzolanic reaction and the higher moisture content will mean more water is released at the onset temperature in the PFA+OPC paste.

Dehydration of cement phases will cause weakening of the cement matrix and increase pore pressures due to release of water vapour. The low temperatures at the 
onset of scabbling of cement pastes indicate that scabbling is driven by the evaporation of free and interlayer water and the release of chemically combined water during cement phase decomposition. The higher content of both free water and C-S-H in the PFA+OPC paste, compared to those for OPC, results in greater loss of evaporable water and cement phase decomposition detected in the TGA. Combined with reduced permeability of PFA+OPC paste, this suggests that pore pressure spalling is the mechanism responsible for the larger volume removal of the PFA+OPC paste compared with the OPC paste. Assuming that the two cement pastes have similar thermal gradients, as they are both homogeneous materials, the large difference in volume removal indicates that thermal stresses are not the cause of scabbling in cement pastes.

\subsection{Scabbling of Mortar and Concrete: Effect of Ag- gregate Addition}

The mortar experienced slightly higher volume removal (Figure 4) and larger debris sizes (inferred from the larger temperature fluctuations in Figure 8) compared to the PFA+OPC cement paste. The increased size of debris suggests that the sand particles act as reinforcement causing larger fragments to be removed. This can also be inferred from the deeper and narrower shape of the trough profiles of PFA+OPC paste compared to the wider and shallower profile of the mortar (Figure 3), which indicates that the reinforcement effect of the sand caused more material removal outside of the hotter central area of the laser beam.

Concrete specimens experienced less volume removal than the mortars. The reinforcement effect would be essentially the same, but the larger size of coarse aggregates make them more difficult to dislodge than sand particles. Material ejection would take place if either the coarse aggregate is fractured, as a result of thermal degradation, or a deeper fracture plane is formed beneath the aggregate. Both mechanisms require extra energy and longer interaction times.

An alternative cause for variation in volume removal could be the difference in thermal properties of the specimens. The high porosity of cement paste results in lower thermal conductivity [33]. Therefore by replacing part of the cement paste content with aggregate, the overall thermal conductivity will be increased allowing for greater heat transfer and less severe thermal gradients. While mortar will have a high proportion of conductive silica sand, the larger cement paste content (Table 1) will mean the mortar will have a lower thermal conductivity than the concretes.
Inclusion of aggregates reduces the content of cement paste greatly, increasing the rock content from $0 \%$ for the cement pastes, to $56 \%$ for the mortar and $78 \%$ for the concretes, which in turn causes vast reductions in porosity, moisture content (Table 3) and permeability. As a result there is less free, interlayer and chemically combined water available within the specimens to be released and aid pore pressure spalling. Combining this with the greater resistance to material removal due to the 'reinforcing effect', it leads to greater temperatures being required for the onset of scabbling to occur.

The temperature of the onset of scabbling for the basalt concrete is higher than the limestone concrete. The higher porosity of the limestone rock (Table 3 ) may enable pore pressures to build within the aggregate pieces reducing the reinforcement effect increasing scabbling. The temperature of the onset for mortar is similar to that of limestone concrete, the increased proportion of cement paste may have a similar effect as the high porosity of the limestone rock. The temperature at the onset of scabbling of cement pastes is even lower. Considering the larger proportion of cement phases (and therefore available water) in the cement pastes and the the lack of reinforcing particles, lower temperatures would increase pore pressures and reduce resistance sufficiently to trigger scabbling.

Hilton [8, 9] found that limestone concrete scabbled effectively but concretes with basalt or granite aggregates vitrified, preventing scabbling. In this study basalt concrete experienced a lower volume removal than limestone concrete, with some vitrification (Figure 2 ), but the volume of material removal from basalt concrete was still far greater than what has been reported in the literature $[7,8]$. The mineralogical composition of the basalt was not analysed in this study (nor reported in the earlier studies $[7,8]$ ), but since the melting temperatures of all minerals in basalts (olivine, pyroxene and plagioclase) are above $1000^{\circ} \mathrm{C}$ [48], and the scabbling of concrete occurred at a lower temperature range $\left(400-700^{\circ} \mathrm{C}\right)$, it can be assumed that the difference in volume removal is due to different cement paste characteristics of the two materials. Increased vitrification noticed in the earlier study indicates a lower rate of scabbling. Small amounts of vitrification in the mortar surrounding the aggregates can be seen in the limestone concrete specimens (LCA, LCS in Figure 2) along with the whitening of the exposed limestone aggregate, the cause of which could be decarbonation of the calcium carbonate, similar to that seen in the limestone rock specimen (LRA). Blair [4] suggested the release of carbon dioxide during decarbonation of calcium carbonate in limestone aggregates was responsible for increas- 
ing pore pressures and subsequently inducing fracture. Scabbling takes place at temperatures below that of calcium carbonate (vaterite or calcite) decarbonation for all specimens tested in this study, suggesting that calcium carbonate decarbonation is not the primary mechanism responsible for laser scabbling.

\subsection{Scabbling of Rock}

The rock specimens had much lower volume removals compared to the concrete specimens with corresponding aggregates. Limestone rock experienced almost no volume removal whereas basalt rock underwent small scale scabbling. Basalt rock is more heterogeneous than limestone rock and as a result more differential expansion between constituents could be the cause for the greater degree of volume removal.

Basalt rock debris was thinner than basalt concrete debris (Figure 5) suggesting different mechanisms were responsible for the scabbling of each specimen. Vitrification of basalt rock debris showed that higher temperatures were reached in trials on basalt rock than those on basalt concrete, again indicating that different mechanisms were causing the scabbling.

The lower volume removal of limestone rock compared to the basalt rock suggests the greater porosity of the limestone (Table 3) was not a determining factor of scabbling success.

\subsection{Scabbling of Cement Pastes, Mortar and Con- cretes: Effect of Saturation}

The laser scabbling process took place in both saturated and air dried specimens. The volume removal was similar in some cases, and different in others, with no clear trend. According to BS 8110-2:1985 [46] and Copier [23], a moisture content of $3 \%$ and above (by mass) is required for explosive spalling to occur. In this study all tested specimens had a moisture content above 3\% (Table 3).

The two cement pastes (PFA+OPC and OPC) and the limestone concrete showed little difference in volume removal for the two moisture contents. Larger volume removals were recorded for air dried than saturated specimens of basalt concrete $(70 \%)$ and mortar $(20 \%)$. The expected increase of scabbling with the increase in degree of saturation was not observed for any of the investigated compositions. This suggests that the increase of pore pressures due to evaporation of free water was not a critical mechanism driving the scabbling.

It has been identified that vitrification is more prominent in saturated specimens compared to air dried specimens. The reason for this is unknown and requires further investigation.
It should be noted that the saturated cement pastes produced smaller debris sizes than the air dried cement pastes. Smaller debris sizes for similar volume removal suggests a higher frequency of smaller fragment ejections in saturated specimens. This indicated that the higher moisture content would increase the effect of pore pressure spalling, whereas the materials with lower moisture content would require longer interaction times, potentially to allow more time for thermal stresses to develop.

\section{Conclusions}

The aim of this study was to detect key mechanisms that control laser scabbling of concrete. The first step was to establish an experimental procedure for characterizing the scabbling behaviour of concrete. This procedure was then applied to a wide range of specimens with different material characteristics, that may have a significant effect on the process.

\subsection{Key Characteristics of Scabbling Behaviour}

The results of this study show that the scabbling behaviour of each material can be characterized by time histories of average surface temperature of the exposed area of the specimens. These temperature time histories provide data on (i) time and temperature at the onset of scabbling, (ii) rate of temperature changes during scabbling, and (iii) temperature fluctuations during scabbling. The temperature at the onset of scabbling can be related to results of DTA/TGA and used to detect which thermal reactions are critical to the initiation of scabbling. Temperature fluctuations during scabbling (their amplitudes and frequency), combined with mass loss measurements, provide data on the effectiveness of the process (mass removal), as well as size of debris, which indicates a particular mechanism. The results showed distinct differences between these characteristics of scabbling behaviour for different materials.

\subsection{Effects of Material Composition on Scabbling}

The results show that the laser scabbling process is significantly affected by the material composition, with clear differences between cement pastes with different binder mixes; between cement pastes, mortars and concretes; and between concretes with the two different types of aggregates used in this study.

The use of $25 \%$ OPC replacement with PFA has a major effect on scabbling in cement pastes, in this case increasing the volume removal by almost 3 times for 
40s interaction time, regardless of the degree of saturation of the material. This could be a result of the increased amount of water (free and bound) and/or reduced permeability of PFA+OPC paste, both contributing to an increase in pore pressures, as well as changes in the chemical composition of the cement phases, which would contribute to both the release of chemically bound water and a reduction in tensile strength of the material.

The temperature at the onset of scabbling is higher for compositions with lower cement paste content. This could be a result of two mechanisms: (i) by introducing aggregates and reducing the content of cement paste (per unit volume), a higher temperature is required to release sufficient water from cement phase decomposition to produce sufficient pore pressures, and (ii) aggregates act as reinforcement, increasing the tensile strength of the material and postponing scabbling.

This study suggests that thermo-mechanical effects of aggregates are more prominent than their thermochemical effects. The results show that calcium carbonate decarbonation and the $\alpha$-quartz to $\beta$-quartz inversion are not the primary mechanisms responsible for laser scabbling, as these processes occur at temperatures that are higher than the temperatures at the onset of scabbling for all materials. In basalt concrete the melting of aggregates creates a vitrified layer that prevents further scabbling; whereas the limestone concrete continues to scabble over a longer period, maintaining a nearly constant surface temperature. The largest volume removal in mortar specimens can be explained by the combined action of the two main mechanisms: larger pore pressures compared to concrete (due to larger cement paste content), and higher scabbling temperatures (due to increased tensile strength), resulting in less frequent scabbling, but much larger fragments when compared to the cement pastes.

These results suggest that laser scabbling is generally driven by processes that take place in the cement paste, with aggregates (fine and coarse) influencing the process by increasing tensile strength, which postpones the onset and increases the size of fragments during scabbling.

\subsection{Effect of Degree of Saturation}

The results of this study showed that the size of fragments was generally smaller, and vitrification was more prominent, for saturated specimens compared to air dried specimens, but the higher degree of saturation did not lead to increased volume removal. This indicates that the presence of free water does affect the process, but is not a key factor controlling its effectiveness.

\section{Acknowledgements}

The authors would like to thank the UK Engineering and Physical Sciences Research Council (EPSRC) for the financial support for this study and the EPSRC Engineering Instrument Pool for lending the equipment (FLIR SC640 and the Phantom V5.1) used in this study. The authors are also grateful to CEMEX UK and Longcliffe Ltd for providing aggregates for the test specimens.

\section{References}

[1] S. Burke, Concrete decontamination. a literature review, Technical report AEEW-R-2609, Winfrith, United Kingdom Atomic Energy Authority, Winfrith (March 1990).

[2] T. Hirabayashi, Y. Kameo, M. Myodo, Application of a laser to decontamination and decommissioning of nuclear facilities at jaeri, in: Advanced High-Power Lasers and Applications, International Society for Optics and Photonics, 2000, pp. 94-103.

[3] L. Li, W. Steen, P. Modern, J. Spencer, Laser removal of surface and embedded contaminations on/in building structures, in: Optics for Productivity in Manufacturing, International Society for Optics and Photonics, 1994, pp. 84-95.

[4] K. Blair, The interaction of $\mathrm{CO}_{2}$ lasers with concrete and cement materials, Ph.D. thesis, University of Liverpool, Liverpool (June 1996).

[5] D. MacCallum, J. Norris, Laser concrete ablation scaling effects., in: ICALEO : 27 th international congress on applications of lasers and electro-optics., Laser Institute of America, 2008, pp. 143-149.

[6] J. Dowden, A. Lazizi, E. Johnston, S. Nicolas, A thermoelastic analysis of the laser scabbling of concrete, Journal of Laser Applications 13 (4) (2001) 159-166.

[7] L. Nguyen, Removal of surface concrete with high power Yb fibre lasers, Technical report 17800/1/07, TWI Ltd, Granta park, Cambridge (October 2007).

[8] P. Hilton, Scabbling of dry and wet concrete and submerged concrete, Technical report 18039/1/08, TWI Ltd, Granta park, Cambridge (December 2008).

[9] P. Hilton, The potential of high power lasers for concrete scabbling and pipe cutting in nuclear decommissioning, Technical report 19124/1/10, TWI Ltd, Granta park, Cambridge (March 2010).

[10] T. Thomas, E. Johnston, J. Spencer, High power Nd:YAG scabbling of concrete. 2nd progress report, Technical report $88277 / 81 / 02$, TWI Ltd, Granta park, Cambridge (April 2002).

[11] W. Steen, J. Mazumder, Laser material processing, Springer, 2010.

[12] E. Johnston, J. Spencer, High power nd:yag scabbling of concrete. 1st progress report, Technical report 88277/48/98, TWI Ltd, Granta park, Cambridge (December 1998).

[13] R. Connolly, The spalling of concrete in fires, Ph.D. thesis, Aston University (1995).

[14] G. Khoury, Y. Anderberg, Concrete spalling review, Technical report, Swedish national road administration (June 2000).

[15] G. Sanjayan, L. Stocks, Spalling of high-strength silica fume concrete in fire, ACI Materials Journal 90 (2) (1993) 170-173, cited By (since 1996)95.

[16] Y. Anderberg, Spalling phenomena of HPC and OC, in: Proceedings of the international workshop on fire performance of high-strength concrete, NIST, Gaithersburg, 1997. 
[17] S. Chan, X. Luo, W. Sun, Effect of high temperature and cooling regimes on the compressive strength and pore properties of high performance concrete, Construction and Building Materials 14 (5) (2000) 261-266.

[18] L. Phan, Pore pressure and explosive spalling in concrete, Materials and structures 41 (10) (2008) 1623-1632.

[19] Y. Fu, L. Li, Study on mechanism of thermal spalling in concrete exposed to elevated temperatures, Materials and structures 44 (1) (2011) 361-376.

[20] K. Hertz, Danish investigations on silica fume concretes at elevated temperatures, ACI Materials journal 89 (4) (1992) 345347.

[21] S. Chan, G.-F. Peng, M. Anson, Fire behavior of highperformance concrete made with silica fume at various moisture contents, ACI Materials Journal 96 (3) (1999) 403-409.

[22] H. Malhotra, Spalling of concrete in fires, Construction Industry Research and Information Association, 1984.

[23] I. Copier, The spalling of normalweight and lightweight concrete on exposure to fire, HERON 24 (2) (1979) 1-92.

[24] H. Taylor, Cement chemistry, 2nd Edition, Thomas Telford Publishing, London, 1997.

[25] B. EN, 12390-7. Testing hardened concrete-part 7: density of hardened concrete, European Committee for Standardization.

[26] ISO, Condition monitoring and diagnostics of machinesThermography-Part 1: General procedures, ISO 184341:2008(E), International Organization for Standardization, Geneva, Switzerland (2008).

[27] B. Peach, M. Petkovski, J. Blackburn, D. Engelberg, Laser scabbling for nuclear decommissioning: Effect of concrete composition on volume removal efficiency, Proceedings of 2nd International Symposium on Cement-based Materials for Nuclear Wastes (NUWCEM 2014, Avignon, France) "to be published".

[28] J. Zhao, J.-J. Zheng, G.-F. Peng, K. van Breugel, Prediction of thermal decomposition of hardened cement paste, Journal of Materials in Civil Engineering 24 (5) (2011) 592-598.

[29] G.-F. Peng, Z.-S. Huang, Change in microstructure of hardened cement paste subjected to elevated temperatures, Construction and building materials 22 (4) (2008) 593-599.

[30] W. Czernin, Cement chemistry and physics for civil engineers, Bauverlag, 1980.

[31] ASTM C856-95e1 standard practice for petrographic examination of hardened concrete (2011).

[32] H. Hilsdorf, A method to estimate the water content of concrete shields, Nuclear Engineering and Design 6 (3) (1967) 251-263.

[33] U. Schneider, U. Diederichs, C. Ehm, Effect of temperature on steel and concrete for PCRV's, Nuclear Engineering and Design 67 (2) (1982) 245-258.

[34] E. Stepkowska, J. Blanes, A. Justo, M. Aviles, J. PerezRodriguez, Thermo XRD-analysis of two aged cement pastes, Journal of thermal analysis and calorimetry 80 (1) (2005) 193199.

[35] V. Lilkov, O. Petrov, Y. Tzvetanova, P. Savov, Mössbauer, DTA and XRD study of Portland cement blended with fly ash and silica fume, Construction and Building Materials 29 (2012) 3341.

[36] I. Odler, S. Abdul-Maula, Possibilities of quantitative determination of the AFt-(ettringite) and AFm-(monosulphate) phases in hydrated cement pastes, Cement and Concrete Research 14 (1) (1984) 133 - 141.

[37] L. Alarcon-Ruiz, G. Platret, E. Massieu, A. Ehrlacher, The use of thermal analysis in assessing the effect of temperature on a cement paste, Cement and Concrete Research 35 (3) (2005) 609613.

[38] T. Harmathy, Thermal properties of concrete at elevated temperatures, Journal of Materials 5 (1) (1970) 47-74.
[39] G. Khoury, B. Grainger, P. Sullivan, Transient thermal strain of concrete: literature review, conditions within specimen and behaviour of individual constituents, Magazine of concrete research 37 (132) (1985) 131-144.

[40] W. Dias, G. Khoury, P. Sullivan, Mechanical properties of hardened cement paste exposed to temperatures up to $700^{\circ} \mathrm{C}(1292$ F), ACI Materials Journal 87 (2) (1990) 160-166.

[41] A. Neville, Properties of concrete., 4th Edition, Harlow, UK: Pearson Education Limited, 1997.

[42] L. Black, C. Breen, J. Yarwood, C.-S. Deng, J. Phipps, G. Maitland, Hydration of tricalcium aluminate $(\mathrm{C} 3 \mathrm{~A})$ in the presence and absence of gypsum-studied by raman spectroscopy and Xray diffraction, Journal of Materials Chemistry 16 (13) (2006) 1263-1272.

[43] B. Ylmaz, A. Olgun, Studies on cement and mortar containing low-calcium fly ash, limestone, and dolomitic limestone, Cement and Concrete Composites 30 (3) (2008) 194 - 201.

[44] B. Lothenbach, K. Scrivener, R. Hooton, Supplementary cementitious materials, Cement and Concrete Research 41 (12) (2011) 1244-1256.

[45] A. Palomo, A. Fernández-Jiménez, G. Kovalchuk, L. Ordoñez, M. Naranjo, OPC-fly ash cementitious systems: study of gel binders produced during alkaline hydration, Journal of materials science 42 (9) (2007) 2958-2966.

[46] Structural use of concrete - Part 2: Code of practice for special circumstances, BS 8110 (1985).

[47] V. Papadakis, Effect of fly ash on portland cement systems: Part I. low-calcium fly ash, Cement and Concrete Research 29 (11) (1999) 1727-1736.

[48] W. G. Ernst, Earth materials, Englewood Cliffs, New Jersey: Prentice Hall, 1969. 